\title{
Persistently learning: How small-world network imprints affect subsequent firm learning
}

\section{Bilian Ni Sullivan}

The Hong Kong University of Science and Technology, Hong Kong

\author{
Yi Tang \\ The Hong Kong Polytechnic University, Hong Kong
}

\section{Christopher Marquis}

Cornell University, USA

\begin{abstract}
We integrate and extend organizational imprinting and organizational learning theories in a study of how firms' small-world networks at founding have enduring effects on firm learning. We show that firms embedded in networks having denser clustering and shorter path lengths at founding are subsequently more inclined toward exploratory learning. We also demonstrate that subsequent network positions (closeness centrality and structural holes) strengthen the initial small world network imprinting effect. Results based on a sample of US venture capital firms from 1995 to 2003 largely support our hypotheses. Contributions to imprinting theory, the organizational learning literature, and inter-firm network studies are discussed.
\end{abstract}

\section{Keywords}

Network imprinting, organizational learning, small-world networks, venture capital firms

The extent to which the effect of social networks on actors is transitory or enduring is a key unresolved issue in organizational theory. Burt (2002), for instance, hypothesized that the effects of ties that bridge different network cliques are fleeting because the benefits of such ties decay quickly as informational benefits expire. Other researchers have described a more complex process whereby some network effects are short-lived while others last. For example, some have found that the effects of network closure endure, yet they have also confirmed Burt's intuition that bridging ties

\section{Corresponding author:}

Bilian Ni Sullivan, Department of Management, School of Business and Management, The Hong Kong University of Science and Technology, Clear Water Bay, Kowloon, Hong Kong.

Email: mnbilian@ust.hk 
have a short life (Baum et al., 2012; Soda et al., 2004). Others have described the effects of social ties to be extremely persistent (Marquis, 2003; Walker et al., 1997). In a study of Nashville lawyers, for instance, associates' early career mentoring networks were found to have a persistent effect on the later performance of their firms, presumably as a result of early socialization and learning (McEvily et al., 2012).

Much of this literature has examined the lasting effects of specific ties or egocentric network relations of individual actors. Less attention has been paid to the potential persistent effects of the overall network structure at founding. Such a gap is important to fill given that structural properties of global networks, such as density or cohesion have been shown to be important for network members' behavior and performance (Coleman, 1988; Sullivan and Tang, 2012). And, if network effects are long-lasting (McEvily et al., 2012), then effects stemming from the global network structure at firm founding are likely persistent.

Furthermore, in order to better understand the mechanisms through which the initial global networks influence firms, it is also important to consider the multi-level nature of network effects. Global structural characteristics and individual firm- level network positions likely interact, yet, empirical and theoretical examinations of such cross- level situations are rare (Brass et al., 2004). In particular, prior research has not yet examined how the initial global network structures and a firm's current egocentric network positions interact to affect a firm's behavior and performance. Without careful examinations of such multi-level processes, our understanding of the mechanisms affecting network effects remains limited and incomplete.

In this study, we examine the influences of initial small-world networks at a firm's founding on the learning behavior of the firm, and how these imprinted effects change over time as firms' egocentric network positions vary. Small-world networks ${ }^{1}$ are characterized by the co-existence of highly clustered local groups and short network paths linking different clusters. The prevalence and importance of small-world networks to firm behavior and performance have been well documented in contexts as diverse as German corporate ownership (2001), American boards of directors (Davis et al., 2003), and Canadian investment syndicates (Baum et al., 2003).

Drawing upon the imprinting literature indicating that early established routines are typically imprinted (Marquis and Tilcsik, 2013; Stinchcombe, 1965), we contend in this study that the routines established by the firms due to their initial exposure to global network structures (e.g. a smallworld network) can be imprinted and thus have a long-lasting effect on subsequent firm behavior and outcomes. Our core hypothesis is that the extent to which firms have a small-world network imprint (i.e. the extent to which the global network structure at founding has small-world properties) leads to an enduring positive impact on a firm's tendency to conduct exploratory learning in subsequent time periods. Furthermore, building on the network literature that has shown the importance of network position to information and knowledge acquisition activities (Burt, 2000), we hypothesize that the influence of the small-world network imprint on subsequent firm exploration could vary depending on a firm's current egocentric network positions. We examine these hypotheses in an empirical study of small-world network imprinting and firms' subsequent learning using data on US venture capital (VC) firms from 1995 to 2003.

By examining in detail the mechanisms linking the initial small-world network structure and a firm's network positions to its exploratory learning behavior, we make the following contributions. First, our article contributes to the organizational learning literature (March, 1991) and imprinting theory (Marquis and Tilcsik, 2013; Stinchcombe, 1965) by showing how initial imprinted learning routines affect subsequent firm adaption. While learning and imprinting processes are typically seen as contradictory (Marquis and Huang, 2010), our approach suggests that they can also be seen as complementary - adaptive routines can be imprinted and they can continuously affect a firm's subsequent learning processes. 
Second, our study contributes to imprinting theory by showing that imprinting effects can be positively moderated by firms' current network positions. That is, firms occupying particular network positions may be more influenced by initial small-world networks than firms with other positions. This contingency-based approach helps to reveal some of the organization-level mechanisms of imprinting, which have been neglected by prior work (Johnson, 2007; Marquis and Huang, 2010). We aim to show not only that initial learning facilitated by firms' small-world network structures at founding is enduring and has lasting performance benefits, but also how these effects can change with time depending on a firm's network positions.

Finally, our study furthers understanding of the interplay among social networks at different levels, which is an under-explored topic in the extant literature (Brass et al., 2004). Doing so allows us to delineate the underlying mechanisms linking social networks to firm behaviors and performance outcomes.

\section{Theory and hypotheses}

Organizational theorists have long suggested that initial economic, political, and cultural conditions at the time of a firm's founding can have persistent impacts on a firm's behavior and outcomes (Stinchcombe, 1965). According to Stinchcombe (1965), organizations are established by drawing on resources available in the founding context, and as a result their initial structures, strategies and characteristics reflect the environment at founding. In addition, due to inertia and the institutionalization of initially established routines (Hannan and Freeman, 1987; Marquis and Tilcsik, 2013), these characteristics persist even when external conditions change. Thus, organizations enduringly exhibit vestiges of their context of establishment, or founding imprints. Imprinting processes have been shown to have a persistent impact on diverse items such as firm structures (Marquis, 2003; Stinchcombe, 1965), strategies (Boeker, 1988; Marquis and Huang, 2010), ability to adapt (Kogut and Zander, 2000; Tucker et al., 1990), competitiveness (Carroll and Hannan, 1989; Swaminathan, 1996), and performance (Eisenhardt and Schoonhoven, 1990; Romanelli, 1989).

While many studies have focused on the effects of network change (e.g. Baum et al., 2004; Sullivan et al., 2007), researchers have also begun to realize that networks and network effects on firms are persistent (Kim et al., 2006) and so susceptible to imprinting processes. For example, Marquis (2003) showed that the inter-corporate network structures of companies founded in cities established during the industrial revolution were imprinted and that new network members imitated the existing pattern such that the imprint was maintained. Similarly, research on the development of biotechnology firm networks found them to be path dependent following founding (Walker et al., 1997). And, McEvily et al. (2012) found that bridging ties in employee's mentor networks can have both contemporaneous and long-lasting effects.

The literature, however, is not fully clear on how the characteristics of a global network structure (e.g. small-world networks) at firm founding have an enduring effect on a firm and, furthermore, how a firm's network positions may create variation in the effects of such a founding imprint. Given that network structures do influence firm behavior and performance (e.g. Ahuja, 2000; McEvily and Zaheer, 1999; Peng and Luo, 2000; Podolny, 2001), we posit that the small-world network properties at founding have enduring behavioral implications. In our hypotheses below, we draw specifically on the literature on networks and learning and describe how small-world network structures at firms' founding affect the firms' subsequent learning behavior and how such processes are also affected by a firm's egocentric network positions.

\section{Small-world networks at founding and firm learning}

Researchers have found that in certain networks, dense local clustering goes hand in hand with short paths linking partners, thus forming the so-called "small-world networks" (Watts, 1999). 
While research on the benefits of small-world networks is not fully conclusive (for a review see Uzzi et al., 2007), a number of studies have shown that embeddedness in a small-world network can enhance a firm's performance by directing and speeding up the information exchanges among different actors in the network (Fleming et al., 2007). For example, in a study of the collaborative network among Broadway artists, Uzzi and Spiro (2005) found that the creativity of small-world network members increased to a certain extent and then declined. Schilling and Phelps (2007) revealed that firms created more knowledge when they were in networks characterized by both high clustering and short average path lengths (PLs; a small world). In a study of US VC firms, Sullivan and Tang (2012) found that small-world networks have a positive effect on the VC firms' performance and that the ones with a strong absorptive capacity are more likely to benefit from small-world networks.

These studies illustrate that the benefits of small-world networks reside in the fact that they grant their actors much quicker access to novel and diverse information from different groups. While dense local network clustering enables more efficient transmission of information and other resources among the actors (Etzkowitz et al., 2000; Reagans and McEvily, 2003), reachability as a result of short path connections among clusters allows actors to obtain novel ideas from distant partners (Schilling and Phelps, 2007). Actors in small-world networks are more likely to avoid information redundancy while accessing different information quickly through contacts with different clusters than those not in small-world networks (Fleming et al., 2007).

Relative to those not in a small-world network, firms embedded in a small-world network are more likely to develop routines for searching beyond organizational boundaries as distant information becomes more accessible. While firms inherently tend to be more exploitative and more likely to focus on searching locally (March, 1991), those with access to more novel information transmitted within a network are more likely to have the chance to evaluate distant business practices and opportunities. Consequently, it is more likely for those firms to conduct exploratory learning, defined as learning by exploring new ideas, new possibilities, and new opportunities (March, 1991). Organizational routines to explore opportunities are likely to be established in firms that often face situations where new information needs to be evaluated and decisions need to be made in response. For instance, firms that often receive new information from their industry are likely to develop certain routines for quickly analyzing, digesting, and absorbing the new information. These routines enable the firms to overcome the tendency to search locally only, leading to a higher likelihood of exploring new business opportunities.

The persistent learning effect of an initial small-world network, of course, can come from the possibility that such a network structure can persist over time in ways as illustrated in previous literature (Kim et al., 2006; Marquis, 2003). Beyond the impact of network inertia and stability over time, however, our study moves one step further to examine how routines established during a firm's initial exposure to certain properties of a global network result in the long-lasting imprinting effect of initial small-world networks.

Routines of distant search and exploration are likely to be imprinted for firms embedded in a small-world network at founding due to the following processes. First, compared to a non-smallworld network, the relatively continuous inflow of diverse and novel information from a smallworld network is likely to enable firm founders to select and implement more adaptive business models. The initial business models selected by the founders have been shown to affect firms' later choices of strategic actions (Baron et al., 1996, 1999; Hannan et al., 1996), so exploratory business models selected by the founders can have long-term behavioral and performance implications. Firms employing such business models are likely to explore more business opportunities. Second, consistent with prior research findings that early established capabilities are persistent and can affect future strategic choices (Boeker, 1988, 1989; Kogut and Zander, 1992), a more general capability can be developed through the establishment of exploratory learning routines for search and 
knowledge absorption and can be used subsequently. Finally, at a general level, the quick diffusion of certain practices leading to more exploration would likely become industry norms, which would in turn induce firms to replicate such practices and consequently aid exploratory learning in the long run (DiMaggio and Powell, 1983; Haunschild and Miner, 1997; Meyer and Rowan, 1977). Therefore, we have the following hypothesis:

Hypothesis 1 (H1). Firms with a higher degree of small-worldness (i.e. a higher small-world quotient) in their network at founding tend to engage in higher degrees of exploration in subsequent periods.

\section{Subsequent network positions and imprinting persistence}

While firms embedded in a small-world network might be more likely to explore than those not in a small-world network as hypothesized above, firms' egocentric network positions may affect the extent to which they continue to be influenced by the initial small-world structures. As discussed earlier, the small-worldness of a network is essentially composed of two elements, clusters where actors are closely linked to each other, and a few actors who serve as bridges connecting different clusters. While in general all firms could benefit from a small-world network, in terms of exploring new opportunities and new possibilities, firms with more ready access to different clusters are more likely to experience benefits than those that are part of a cluster yet only indirectly connected to other clusters. The network configuration is dependent on how closely actors are linked to each other and if an actor occupies a broker position. These characteristics determine how quickly and easily the firm is able to access new information in a small-world network.

\section{Closeness centrality}

In network studies, closeness centrality captures the extent to which an actor is closely linked to others (Freeman, 1979; Wasserman and Faust, 1998) and structural holes indicate the existence of brokerage opportunities (Burt, 1992). In the following, we develop hypotheses on how a firm's current closeness centrality and structural holes can moderate the imprinting effect of a smallworld network. As discussed, the key mechanism enabling the persistent learning effect of the small-world network at a firm's founding is the initial establishment of organizational routines leading the firm to distant search and exploration for new ideas and opportunities. Since a smallworld network is composed of clusters (closeness) and bridges (brokerage), initial exploratory routines are developed to handle speed of information access, which is more related to closeness and diversity of information which is more associated with brokerage. Higher degrees of network closeness and brokerage are thus likely to strengthen the influence of initial small-world networks on firm exploration. This is because the role of initial exploratory routines is likely to be more salient due to the continuous fast access to information resulting from network closeness and diverse information access due to brokerage positions.

Since closeness centrality is the inverse of the sum of the average distance from a focal actor to all other actors (Wasserman and Faust, 1998), a higher degree of closeness centrality suggests that the focal actor can reach any other direct and indirect network ties much faster and more efficiently (Freeman, 1979). Empirical examinations of the role of closeness centrality in firm performance, however, have yielded mixed findings. While some scholars have revealed a positive effect of closeness centrality on firm performance (Larcker et al., 2012), others have found that closeness centrality could hurt firm performance. For instance, based on a sample of 480 outside directors from 125 large Korean public trading companies, Lee et al. (2012) found that the closeness centrality of outside board directors could negatively affect a firm's performance and valuation. 
Regardless of its main effect on performance, studies do share the consensus that closeness can facilitate more efficient information transition and acquisition. A high degree of closeness centrality means that a focal actor is in close proximity to all other actors. The actor can maximize the value of closeness centrality if the actor is next to each of the other actors in the network (Wasserman and Faust, 1998). In the context of the small-world network, closeness suggests clustering and speedy transfer of information. For firms in a network position with a high degree of closeness centrality, established distant search and exploratory routines are important to handle the fast and efficient access to information from others. In other words, when the degree of closeness is high, the need for fast information processing is high, and thus the initial distant search and exploratory routines established to process such information become more important. In addition, a high degree of closeness is likely to enable the firms to continuously update and develop their existing distant search and exploration routines so that they can continuously absorb the information quickly. Thus, for firms with higher closeness centrality, the effects of the small-world imprint described in $\mathrm{H} 1$ are likely to be enhanced. Therefore, we have the following hypothesis:

Hypothesis 2 (H2). The positive effect of small-world networks at founding on firm exploration will be stronger for firms with a higher degree of current closeness centrality.

\section{Brokerage}

In addition to the importance of close linkages with other actors, the literature has consistently shown the importance of brokerage, or when the focal actor connects two other actors who are otherwise not connected (Burt, 1980, 1992; Galaskiewicz, 1979; Gould and Fernandez, 1989; Marsden, 1982). For instance, being in a brokerage position allows the focal actor to acquire novel and diverse information from non-redundant network ties (Burt, 1980, 1992, 2004; Galaskiewicz, 1979; Marsden, 1982). Scholars have revealed that actors in brokerage positions have more successful banking deals (Mizruchi and Stearns, 2000), better solutions to problems (Hansen, 1999), and higher bonus compensation (Burt, 2000).

We argue that a focal firm's brokerage position would moderate the small-world network imprinting effect. In the context of a small-world network, given the existence of clusters where actors are closely tied, the role of brokers is essential in accessing and spreading diverse information among different clusters. The more brokerage opportunities a firm has, the more diverse information it can access in a small-world network. This influx of diverse information accessed by these firms would allow for further utilization and enhancement of the exploratory routines established under the influence of initial small-world networks. Therefore, we present the following hypothesis:

Hypothesis 3 (H3). The positive effect of small-world networks at founding on firm exploration will be stronger for firms with more brokerage opportunities.

\section{Method}

\section{US venture capital industry}

The VC industry in the United States has exhibited dramatic growth and an increased level of sophistication over the past 40 years. While the total investment amount by VC funds increased over the years (Gompers and Lerner, 2001; MoneyTree Survey, 2004), the industry experienced significant fluctuations in both the number of existing VC firms in the market and the number of investment rounds made from 1995 to 2003 (Sullivan and Tang, 2012). 
Rather than running specific operations for firms, the main goal for VC firms is to reap quick returns from a firm's growth. They aim to "exit" their investment by either having their firms issue stocks through an initial public offering (IPO), or getting other firms to acquire their firms (Podolny and Feldman, 1997). But since most of the start-up companies with VC investment fail before they are acquired or before they manage to issue an IPO, VC firms face a high risk that is offset only by the potential for high returns (Cochrane, 2005; Podolny, 2001). Under such a high degree of uncertainty, access to information plays a critical role in VC firms' decision making. Network connections in the $\mathrm{VC}$ industry that facilitate information exchange among network partners are thus essential to firm survival and performance (Podolny, 2001).

\section{Sample and data}

The firm sample used in our study contains US VC firms that made investments between 1995 and 2003. Information on co-investment from 1990 to 1994 was also used to construct the network variables for 1995. Data were collected from the SDC Venture Economics and M\&A databases, which have been recording investments of VCs since the early 1970s and M\&A transactions since 1979, respectively (Podolny, 2001; Sorenson and Stuart, 2001). We selected the study period based on the observation that VC industries became prominent after the 1990s and also underwent significant ebbs and flows during that period (De Clercq et al., 2006).

Small-world network measure. We used joint (syndicated) investments among the VC firms to construct network variables. Previous research has employed co-investments among VC firms to construct network measures where researchers assumed that firms form network ties if they make joint investments (Podolny, 2001; Sorenson and Stuart, 2001). Viewing co-investments as network ties is substantively meaningful since syndicates can facilitate referrals for other investments (Fried and Hisrich, 1994) and can be used as channels to share knowledge (Bygrave and Timmons, 1992) and to resolve informational uncertainties about potential investments (Lerner, 1994). To acquire opinions from others is an important motivation for VC firms to form syndicates (Fried and Hisrich, 1994). Joint investments, therefore, are an appropriate indicator of the inter-firm network ties in the VC industry.

We first constructed an adjacency matrix indicating whether a network tie existed between each pair of VC firms. In the matrix, "1" was coded to indicate that two firms were tied through joint investment in one particular investment round and a " 0 " indicating that they were not. We considered all co-investments in the prior 5 years, assuming that such a relationship will erode over time (Sorenson and Stuart, 2001). That is, if two VC firms have not co-invested within a 5-year time period, it is highly likely that they would not remain close confidants (Sorenson and Stuart, 2001). Collecting data in this prior time window also helped avoid any potential reverse causality problems.

In calculating the small-world quotient, following prior studies, we used industry to define the boundary of small-world networks (e.g. Uzzi and Spiro, 2005). One might expect that VC firms would have a variety of investment opportunities in different industries to explore since VC firms are constantly looking for superior deals to maximize their returns. In reality, however, VC firms tend to be localized in an investment industry, focusing on particular industries (Gupta and Sapienza, 1992; Sorenson and Stuart, 2001). In our particular context, the industry that a VC firm makes its investment in during its founding period is likely to be the industry that VC firm is primarily associated with. A VC firm might make an investment in other industries later on. The industry category that the VC firms invest in reflects the knowledge and expertise that a VC firm might have. For instance, while some VC firms may possess more knowledge of investing in computer-related industries, others may be more familiar with investing in biotechnology 
industries instead. Also, a VC-backed firm that competes in a particular industry will have direct consequences on the performance of the VC firm that is backing it. Finally, the VC firms investing in the same specialized industries are very likely to exchange valuable information among themselves concerning their investments and new opportunities. The use of industry as a boundary is also important for us to test the theoretical mechanism discussed above. Essentially, with such a design, we can demonstrate that it is not the information in the network per se that affects a firm's subsequent behavior, but it is the routines established under the influence of initial small-world networks that affect a firm's subsequent exploration into a different industry that was not the primary investment industry for the VC firm at its founding. That is, once the routines are established, the firm can use such routines to explore opportunities in distant industry spaces. Since geographic space can be another important boundary condition for VC firms to exchange information, in additional analyses, we also employed region to define the boundary for small-world networks, and the results were consistent with those reported in this study.

Therefore, in this study, we constructed our small-world networks in different specialized industries by the VC firms in a particular year. The SDC database categorizes VC-backed firms into 10 industry groups. We found 90 small-world networks ( 10 industries by 9 years) in the sample during the study period.

Following prior literature on small-world networks (Baum et al., 2003; Davis et al., 2003; Fleming et al., 2007; Kogut and Walker, 2001; Newman, 2000; Schilling and Phelps, 2007; Uzzi and Spiro, 2005; Verspagen and Duysters, 2004), two components of a small-world network- the clustering coefficient (CC) and the PL coefficient - were considered. The former represents the degree of local clustering and the latter indicates reachability. To determine the degree of smallworldness of a network, we compared an actual network's PL and CC with those of a random graph of the same size, where random graphs have both very short PLs and low clustering. The actual CC was measured by a weighted overall CC (Borgatti et al., 2002; Newman et al., 2002), which indicates the transitive closure of a graph and is defined as

$$
\mathrm{CC}=\frac{3 \times(\text { number of triangles in the graph })}{\text { (number of connected triples })}
$$

where a triangle is a set of three nodes, each of which is connected to the other two, and a connected triple is a set of three nodes in which at least one is connected to the other two. This indicator ranges from 0 to 1 , with " 0 " indicating no clustering and " 1 " indicating full network clustering. We computed the $\mathrm{CC}$ by applying the "CC" procedure available in the software package UCINET VI (Borgatti et al., 2002). The actual PL was calculated by taking the weighted average of the PLs of all actors in the network (Uzzi and Spiro, 2005).

The random $\mathrm{CC}$ was measured by $\mathrm{k} / \mathrm{n}$, where $\mathrm{n}$ is the number of actors in the network and $\mathrm{k}$ is the average number of relationships per actor (Kogut and Walker, 2001). The random PL was calculated by $\ln (\mathrm{n}) / \ln (\mathrm{k})$ (Kogut and Walker, 2001).

The closer the PL ratio (PL of the actual network/PL of a random graph of the same size) is to 1.0 and the more the $\mathrm{CC}$ ratio exceeds 1.0 (CC of the actual network/CC of a random graph of the same size), the greater the network's "small- worldness" is (Fleming et al., 2007; Uzzi and Spiro, 2005). Therefore, the value of small-world quotient was calculated by CC ratio/PL ratio (Uzzi and Spiro, 2005). For each VC firm, the imprinted small-world quotient was measured as the smallworld score calculated from the network ties formed through the firm's very first investment in the first 5 years after its founding within our sampling period. ${ }^{2}$ For those firms that were not in any syndicated relationships during their first 5 years of operation, the imprinted small-world score was " 0 " (about $3.3 \%$ of the sampled observations). If in subsequent years, a VC firm invested in an 
Table I. Descriptive statistics of small-world networks for different industries.

\begin{tabular}{lrrrr}
\hline Industry & Mean & SD & Min & Max \\
\hline Biotechnology & 6.51 & 1.38 & 4.46 & 8.32 \\
Communications and media & 9.03 & 3.30 & 5.31 & 14.29 \\
Computer hardware & 12.15 & 7.36 & 4.88 & 23.49 \\
Computer software and services & 9.49 & 2.73 & 6.10 & 12.98 \\
Consumer related & 21.61 & 8.12 & 10.20 & 34.13 \\
Industrial/energy & 30.13 & 19.17 & 8.09 & 66.96 \\
Internet specific & 9.84 & 2.32 & 6.77 & 13.14 \\
Medical/health & 7.21 & 1.15 & 5.19 & 8.46 \\
Other products & 39.98 & 11.98 & 24.31 & 64.09 \\
Semiconductors/other electronics & 9.44 & 3.49 & 5.53 & 14.82 \\
\hline
\end{tabular}

SD: standard deviation.

industry in which it had not invested in the first 5 years after its founding, the imprinted small-world score was also " 0 " (about $2 \%$ of the sampled observations). Table 1 summarizes the descriptive statistics of small-world quotient for different industries included in our sample.

Dependent variable. Our dependent variable is the exploratory learning of VC firms, which was measured by a dummy variable indicating whether a VC firm entered a new industry in which it had never invested before in year $t+1$. Prior research has used a VC firm's entry into a new industry to indicate firm exploration (Dimov and Martin de Holan, 2010). As discussed by Dimov and Martin de Holan (2010), firm exploration can be only understood as newness or search for new ideas in relation to a focal firm's specific activities or domains. Examples include patenting in a new technological domain to indicate exploration for technology firms (George et al., 2008) or establishing an operation in a new geographic location (Baum et al., 2000). A VC firm's entry into an industry that the VC firm had never invested in before shares the same feature with those exploration measures, due to the fact that such an entry presents the newness relative to the firm's past or current specific activities.

Since our study focuses on the impact of imprinted small-world networks, it is necessary to control for the impact of small-world networks in the current year. However, simply including the current small-world network as a control variable in the analyses may lead to erroneous estimates because of the high correlation between the imprinted small-world network and the current smallworld network (above 0.94). Therefore, we first ran a regression model where a VC firm's exploration was the dependent variable and the current small-world network was the predictor. The residual from this model indicates the variance in the VC firm's exploration not explained by the current small-world network. We then took the residual from this model as the dependent variable in our subsequent analyses where the current small-world network was excluded from the models.

Moderating variables. This study investigates whether a firm's current network positions, namely closeness centrality and structural holes, moderate the main effect of initial small-world conditions on firm exploration. Firm closeness centrality was measured by a focal firm's average distance to other members of the network (Freeman, 1979), calculated with the following equation

$$
\mathrm{C}_{j}(\mathrm{n}-1)\left[\sum_{\mathrm{i}} \mathrm{d}\left(\mathrm{p}_{\mathrm{i}}, \mathrm{p}_{\mathrm{j}}\right)\right]
$$

where $d\left(p_{i}, p_{j}\right)$ is the path distance between actors $i$ and $j$. 
Structural hole was measured by 1 minus Burt's (1992) measure of constraint

$$
1-\left(p_{i j}+\sum_{q} p_{i q} p_{q j}\right)^{2}
$$

where $\mathrm{p}_{\mathrm{ij}}$ is the proportion of actor i's relations that are invested in actor $\mathrm{j}$, and the formula in the parentheses calculates the proportion of actor i's relations that are directly or indirectly invested in the connections with actor j. We used UCINET VI (Borgatti et al., 2002) to calculate the closeness centrality and structural hole based on the co-investment ties among VC firms in each year.

Control variables. Control variables at the firm, network, and industry level were included. We controlled for the average investment value in each round, since rounds with different investment amounts may give rise to different impetus for investment (Hsu, 2006). We controlled for the average investment stage of all rounds in a particular year, since different investment stage implies the different potential the start-up companies may go IPO or getting acquired (Podolny, 2001). We also controlled for the average of the total number of investors involved in one particular investment round. We further controlled for firm age, firm experience heterogeneity, and prior successful experiences. Firm age was measured by the interval starting from the year when a VC firm first entered the industry until the current year. Firm experience heterogeneity in business activities was measured by an entropy-based diversity indicator (Ancona and Caldwell, 1992): $-\sum p_{i} \ln p_{i}$, where $p_{i}$ is the proportion of prior investment rounds in industry $i$ to the total number of prior investment rounds. The greater the entropy score, the more heterogeneous the focal VC firm's experiences are. Firm cumulated successful experience was measured by the natural logarithm of the cumulated number of prior successful exits, including those achieved through IPOs and acquisitions by other firms.

We controlled for the overall density of each network, measured by the ratio of the number of existing links in one particular network to the number of possible pair-wise combinations of firms in the network, because the rate and extent to which information diffuses increase with density (Yamaguchi, 1994). We used UCINET VI again (Borgatti et al., 2002) to calculate the network density.

We included a set of industry dummies (10 categories with one omitted category as the reference group) to control for any additional industry-level effect on firm performance. Finally, we controlled for the year dummies.

\section{Model}

A firm-year unbalanced panel dataset was used in the analyses. As the imprinted small-world quotient was constant over the years and the dependent variables are continuous variables, random effects regression models were used. To address potential sample selection bias from including only the years when firms made investments, we used Heckman's selection model for our analyses (Heckman, 1979). We first obtained the inverse Mills' ratio (IMR) or the "non-selection hazard" $(\lambda)$ from a random effects probit model (first-stage model) predicting the probability of a firm's involvement in an investment in a particular year, following an approach suggested by Nijman and Verbeek (1992) and Kyriadzidou (1997). We ran this model on the full sample using the firm's age, its number of prior investment rounds, and its performance in the previous year as predictors. The firm's number of prior investment rounds variable was only included in the first-stage model. We 
then included the IMR as a new variable in the subsequent models, which include only those years when the firm made investments.

\section{Results}

\section{Main analyses}

Table 2 presents the descriptive statistics and correlation matrix of the key study variables. A further investigation did not reveal any serious multicollinearity issue: the mean variance inflation factor is 1.70 , with a maximum of 2.83 .

Table 3 presents the random effects regression estimates of VC firm exploration. Model 1 includes the control variables, the moderating variables, and the predictor - imprinted small-world quotient. For the control variables, investment stage was negatively related to firm exploratory learning $(p<.01)$. Network density was also negatively associated with firm exploration $(p<.05)$. The more heterogeneous the firm's experiences are, the greater its exploration $(p<.001)$. The older the firm is, the greater its exploration $(p<.001)$. Consistent with H1, which states that firms in networks having higher degrees of small-world quotient tend to engage in greater exploratory learning, the imprinting effect of small-world quotient was significantly positive $(p<.001)$. Therefore, our $\mathrm{H} 1$ is strongly supported.

Model 2 in Table 3 includes the interaction between small-world quotient and a VC firm's closeness centrality. The result suggests a positive effect $(p<.01)$, which renders support to our H2: a firm's closeness centrality strengthens the positive effect of an imprinted small-world network on firm exploration. Model 3 includes the interaction between small-world quotient and a VC firm's structural holes. We found a positive and significant effect $(p<.001)$. This is consistent with our H3: a firm's brokerage position strengthens the relationship between an imprinted small-world network and firm exploration. Model 4 includes all the variables as the full model and the results in general remained. Thus, overall, we find evidence supporting our predictions that initial small-world quotient has a lasting positive effect on firm exploration, and that a firm's closeness centrality and structural holes can strengthen the positive impact of initial small-world networks.

In addition, we performed supplementary analyses on models where firm performance, indicated by the ratio of IPOs or M\&As to the total number of investment deals, served as the dependent variable. Again we used the residuals from the model where we regressed firm performance on the current small-world network. Table 4 presents the estimates for models where the dependent variable is firm performance. Model 5 in Table 4 includes all the control variables, the moderating variables, and the main predictor-imprinted small-world network. The main effect of closeness centrality and structural holes is not significant. The imprinting effect of the initial small-world network was shown to be significantly positive $(p<.001)$.

We did analyses on the moderating effects of closeness centrality and structural holes with initial small-world networks on firm performance. Interesting to see in Model 6 and 7 in Table 4 is that the interaction effect is significantly negative $(p<.05)$ for closeness centrality and nonsignificant for structural holes. We believe this finding supports our theoretical arguments about the role of initial small-world networks on firm exploration. This suggests that over-exploration might occur under the combined impact of the initial small-world network and the current closeness centrality and structural holes: as the former induces the establishment of routines for firm exploration and the latter motivates the firm to explore further for new opportunities. And, overexploration could hamper a firm's performance (March, 1991). 


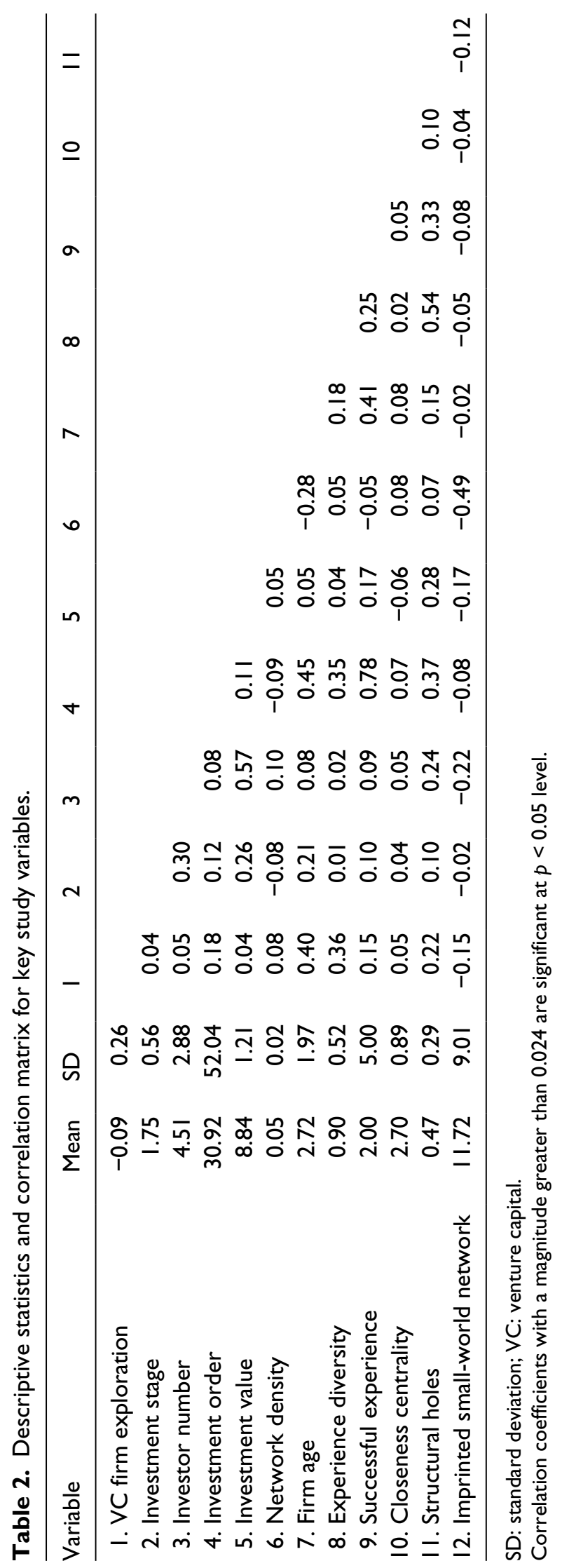


Table 3. Random effects estimates of VC firm exploratory learning.

\begin{tabular}{|c|c|c|c|c|}
\hline Variable & Model I & Model 2 & Model 3 & Model 4 \\
\hline Mean investment stage & $-.012 * *(.004)$ & $-.012 * *(.004)$ & $-.010 *(.004)$ & $-.010 *(.004)$ \\
\hline Mean investor number & $.001(.001)$ & $.001(.001)$ & $.002(.001)$ & $.002(.001)$ \\
\hline Mean investment order & $.000(.000)$ & $.000(.000)$ & $.000(.000)$ & $.000(.000)$ \\
\hline Mean investment value (log) & $.002(.003)$ & $.002(.003)$ & $.002(.003)$ & $.002(.003)$ \\
\hline Network density & $-.74 \mid * *(.260)$ & $-.728 * *(.259)$ & $-.722 * *(.256)$ & $-.715^{* *}(.256)$ \\
\hline Firm age & $.090 * * *(.004)$ & $.091 * * *(.004)$ & $\left..09\right|^{* * *}(.004)$ & $.09 \mid * * *(.004)$ \\
\hline Successful experiences & $.001(.001)$ & $.001(.001)$ & $.001(.001)$ & $.001(.001)$ \\
\hline Experience diversity & $.061 * * *(.007)$ & $.061 * * *(.007)$ & $.062^{* * *}(.007)$ & $.062 * * *(.007)$ \\
\hline Closeness centrality & $.005(.007)$ & $.003(.007)$ & $.0002(.007)$ & $-.001(.007)$ \\
\hline Structural holes & $.009(.013)$ & $.010(.013)$ & $.011(.013)$ & $.011(.013)$ \\
\hline Imprinted small-world network & $.009 * * *(.001)$ & $.010 * * *(.001)$ & $.010 * * *(.001)$ & $.010 * * *(.001)$ \\
\hline $\begin{array}{l}\text { Imprinted small-world } \\
\text { network } \times \text { closeness centrality }\end{array}$ & & $.00 I^{* *}(.0003)$ & & $.0005(.0003)$ \\
\hline $\begin{array}{l}\text { Imprinted small-world } \\
\text { network } \times \text { structural Holes }\end{array}$ & & & $.010^{* * *}(.001)$ & $.010 * * *(.001)$ \\
\hline Inverse mills' ratio & $1.264 * * *(.234)$ & $1.266 * * *(.234)$ & $1.248 * * *(.231)$ & $1.250 * * *(.231)$ \\
\hline Year dummies & Yes & Yes & Yes & Yes \\
\hline Industry dummies & Yes & Yes & Yes & Yes \\
\hline Constant & $-329 * * *(.103)$ & $-308^{* *}(.104)$ & $-.322(.102)$ & $-.309 * *(.103)$ \\
\hline $\mathrm{N}$ & 6096 & 6096 & 6096 & 6096 \\
\hline $\mathrm{R}^{2}$ (overall) & .263 & .264 & .271 & .271 \\
\hline Wald $\chi^{2}$ & || $64.2 \mid$ |*** & $1172.44 * * *$ & $1304.10^{* * *}$ & $1306.62 * * *$ \\
\hline
\end{tabular}

VC: venture capital.

$* * * p<.001,{ }^{* *} p<.01,{ }^{*} p<.05$, two-tailed test; robust standard errors in parentheses.

\section{Discussion}

Anchored in Stinchcombe's (1965) pioneering work on organizational imprinting and the recent efforts extending this research stream to the context of social networks (Marquis, 2003; McEvily et al., 2012), we examined the effects of small-world networks at a firm's founding on the firm's subsequent learning behavior. Studying a large sample from the US VC industry, we found that those firms that were able to initially embed themselves in a network characterized by both high local clustering and short PLs at founding were more likely to conduct exploratory learning than other firms. We further found that such imprinting effects were strengthened by the focal firm's current network positions, namely, its closeness centrality and structural holes, supporting our idea that small-world imprints exert their effects through established routines that increase firm adaptability (exploration). These interaction effects, we believe, result from the firms' network positions enhancing the initial adaptive effects of small-world networks. These results show that there is a complex and contingent relationship between a firm's initial conditions and its subsequent network positions.

Prior research on organizational imprinting has found evidence showing that the conditions at a firm's founding have a significant impact on the firm's subsequent strategic choices and behaviors (Marquis and Tilcsik, 2013). But this line of research has not paid sufficient attention to the role of the initial global network structure in which a firms is embedded on firm subsequent behavior. Our study extends this line of research to the context of small-world networks by exploring the dynamics of the lasting behavioral and performance impact of firms' initial small-world networks. 
Table 4. Random effects estimates of venture capital firm performance (ratio of IPO \& M\&A to the total no. of deals).

\begin{tabular}{|c|c|c|c|c|}
\hline & Model 5 & Model 6 & Model 7 & Model 8 \\
\hline Mean investment stage & $.000(.002)$ & $-.000(.002)$ & $.000(.002)$ & $-.000(.002)$ \\
\hline Mean investor number & $.001(.000)$ & $.001(.000)$ & $.001(.0005)$ & $.001(.0005)$ \\
\hline Mean investment order & $.000 * * *(.000)$ & $.0004 * * *(.0001)$ & $.0004 * * *(.0001)$ & $.0004(.0001)$ \\
\hline Mean investment value (log) & $.004 * * *(.001)$ & $.004 * * *(.001)$ & $.004 * * *(.001)$ & $.004 * * *(.001)$ \\
\hline Network density & $-.264 *(.119)$ & $-.269 *(.119)$ & $-.263^{*}(.119)$ & $-.267 *(.119)$ \\
\hline Firm age & $.002(.001)$ & $.002(.001)$ & $.002(.001)$ & $.002(.001)$ \\
\hline Successful experiences & $-.004 * * *(.001)$ & $-.004 * * *(.001)$ & $-.004 * * *(.001)$ & $-.004 * * *(.001)$ \\
\hline Experience diversity & $-.027 * * *(.003)$ & $-.027 * * *(.003)$ & $-.027^{* * *}(.003)$ & $-.027^{* * *}(.003)$ \\
\hline Closeness centrality & $.006(.003)$ & $.006 *(.003)$ & $.006(.003)$ & $.007 *(.003)$ \\
\hline Structural holes & $.007(.006)$ & $.007(.006)$ & $.007(.006)$ & $.007(.006)$ \\
\hline $\begin{array}{l}\text { Imprinted small-world } \\
\text { network }\end{array}$ & $.00 I^{* *}(.0004)$ & $.001 * *(.0004)$ & $.00 I^{* *}(.0004)$ & $.001 *(.0004)$ \\
\hline $\begin{array}{l}\text { Imprinted small-world } \\
\text { network } \times \text { closeness centrality }\end{array}$ & & $-.0003 *(.000 \mathrm{I})$ & & $-.0003 *(.000 \mathrm{I})$ \\
\hline $\begin{array}{l}\text { Imprinted small-world } \\
\text { network } \times \text { structural holes }\end{array}$ & & & $-001(.0004)$ & $-.0004(.0004)$ \\
\hline Inverse mills' ratio & $.033(.103)$ & $.035(.103)$ & $.030(.103)$ & $.031(.103)$ \\
\hline Year dummies & Yes & Yes & Yes & Yes \\
\hline Industry dummies & Yes & Yes & Yes & Yes \\
\hline Constant & $.054(.046)$ & $.046(.046)$ & $.055(.046)$ & $.031(.103)$ \\
\hline $\mathrm{N}$ & 6096 & 6096 & 6096 & 6096 \\
\hline $\mathrm{R}^{2}$ (overall) & .065 & .066 & .066 & .067 \\
\hline Wald $\chi^{2}$ & $611.48 * * *$ & $616.64 * * *$ & $611.88 * * *$ & $616.40 * * *$ \\
\hline
\end{tabular}

IPO: initial public offering.

$*_{* *}^{*} p<.00 \mathrm{I},{ }^{*} p<.0 \mathrm{I},{ }^{*} p<.05$, two-tailed test; robust standard errors in parentheses.

By showing that network imprinting affects subsequent organizational learning and exploration, our study suggests that imprinted adaptive routines, that is, routines that encourage exploration, are inert yet they can enable future change. One contribution of our study is to show that while the inertial force rooted in routines established during the early life of an organization is important for achieving stabilized organizational blueprints (Hannan and Freeman, 1987), such inertial forces may themselves contain adaptive elements enabling firms to change and adapt quickly, shaping subsequent organizational decision-making and performance. How subsequent organizational activities affect initially established routines is dependent on which aspect of the routines is affected by those activities. Whereas recent literature on organizational learning has suggested structural mechanisms through which firms avoid non-desirable competency traps (Siggelkow and Levinthal, 2003), our study suggests that imprinted adaptive routines resulting from initial exposure to certain global networks might help the firms through exploration to overcome such traps as well.

This research also has important implications for research on small-world networks and organizational learning. Although the importance of small-world networks has been well established across a variety of contexts (Baum et al., 2003; Davis et al., 2003; Fleming et al., 2007), their performance implications for firms have rarely been examined (Schilling and Phelps, 2007; Sullivan and Tang, 2012; Uzzi and Spiro, 2005). More importantly, prior research has yet to consider performance implications of the initial small-world network structure a firm is embedded in when it enters an industry. Therefore, we contribute to the network literature by showing that firms 
continue to draw resources from their initial small-world networks many years down the road, and thus initial small-world networks have long-lasting effects on firm behavior.

Finally, our supplementary analyses on the impact of initial small-world networks on firm performance suggest that while these networks might benefit firms in terms of both processes and outcomes, a firm's current conditions could moderate the main effects differently depending on the nature of those processes and outcomes. Consistent with learning theory (March, 1991), our study seems to suggest that firms that benefit from their initial small-world networks in terms of exploration and firm performance may experience reduced performance benefits if the current conditions (closeness centrality and structural holes in our context) further encourage exploration. This is because this combined effect of enhanced exploration from both imprinted small-world effect and the current network positions will be likely to lead to over-exploration for the firm, which could negatively affect a firm's performance.

In addition to important theoretical implications, our study has significant managerial implications. It suggests that it is essential for managers to make a prudent choice about the first network partner for business collaborations. Prior research has shown that for start-up companies, network partners can serve as signals of the firms' quality to external constituents (Sullivan and Tang, 2013). Our current research further indicates that the selection of a start-up's initial network partners can have profound impact on a firm's subsequent decision-making processes and firm performance. For VC firms, our study also suggests that the choice of firms to invest in not only has a direct impact on the returns from those particular firms but also has a substantial impact on the VC firm's subsequent investment decisions.

Our research is not without limitations. First, because of the peculiarities of the VC industry, the generalizability of our findings might be a concern. The VC industry is extremely uncertain, fastpaced, and full of risks, and in this industry decisions need to be made quickly (Podolny, 2001). The need for quick access to high-quality information might be much bigger in this industry than in other industries, such as traditional manufacturing industries. However, with globalization and the development of advanced technologies, most industries are increasingly experiencing the need to respond to the rapidly changing market demands and the intense competition for limited resources (Friedman, 2005). Therefore, the importance of quick access to high-quality information may differ slightly in degree only rather than in substance. As we have confirmed others' suggestion that there is a positive relationship between experience heterogeneity in the VC industry and VC firm performance (Beckman and Haunschild, 2002; Haunschild and Sullivan, 2002), our findings do appear to be generalizable to various other industries. Future studies could benefit from examining the influences of small-world network imprinting and contingency factors in industries where the information need is not as great. In such industries, the importance of the moderating variables might be weaker.

Second, it is likely that there are additional factors that would moderate the relationship between small-world network imprinting and organizational learning. Those factors may be at different levels, including firm, network, and industry levels. For example, prior research has shown that whether a firm is a generalist or a specialist would affect the extent to which it can cope with environmental conditions (Haunschild and Sullivan, 2002). Also, Beckman and Haunschild (2002) found that the effect of a partner's information heterogeneity is dependent on the characteristics of the tie with that partner. Following the earlier point, industrial category may be one important moderator to consider. The relationship between small-world network imprinting effects and firm learning may be stronger in those industries that are facing a more dynamic environment and relying more on high-quality information to make quick decisions.

The past experience of the focal firm may be another moderator for consideration in future research: a firm's accumulated experience is likely to influence how firms further adapt after founding. For instance, more diverse information from heterogeneous experiences may help firms 
improve and refine existing adaptive routines, easing the impact from the force of inertia. Firms would be likely to modify their established routines as the result of the imprinting small-world network impact such that how activities are structured within the firm does not become stagnant and increasingly unfit over time. A firm's past successful experiences might negatively moderate the positive effect of the imprinted small-world because past successes could lead firms to focus on preserving certain aspects of routines generated from those experiences. As a result, the influences of adaptability associated with routines from the initial small-world networks may be undermined. Future research could benefit from examining these potential moderators to further delineate the boundary conditions of imprinting processes and how imprints change with firm experience.

\section{Conclusion}

By examining how the initial small-world network of sample of US VC firms founded during 1990-2003 affects their subsequent learning, this study integrates and extends organizational imprinting and organizational learning theories. Results show that small-world networks at a firm's founding have a persistently positive effect on subsequent firm exploratory learning and that this effect becomes stronger if the focal firm develops network positions that have a higher degree of closeness centrality or allows it to bridge more structural holes. Given the important role of network imprinting in firm behavior and performance, future studies should further explore both the effects of initial environmental conditions on subsequent firm actions and performance and how these effects vary depending on firm characteristics.

\section{Funding}

This study is partially financially supported by the funding (HKUST6459/05H) from the Research Grant Council of the Government of the Hong Kong Special Administrative Region of the People's Republic of China.

\section{Notes}

1. The extent of simultaneous existence of highly clustered groups and short average PLs in a network has been referred to as small-world connectivity (Schilling and Phelps, 2007) or small-world network (small-world quotient) (Uzzi and Spiro, 2005). To avoid potential confusion of related constructs and to indicate the degree of variation of a network in "small-worldnesss," in this article, we follow Uzzi and Spiro (2005) to use the terms "small-world network" or "small-world quotient" for discussion.

2. We also conducted a robustness check by considering a 3-year window, and the results were largely consistent with those presented here.

\section{References}

Ahuja, G. (2000) "Collaboration Networks, Structural Holes and Innovation: A Longitudinal Study," Administrative Science Quarterly 45: 425-55.

Ancona, D. G. and Caldwell, D. F. (1992) "Bridging the Boundary: External Activity and Performance in Organizational Teams," Administrative Science Quarterly 37: 634-61.

Baron, J., Burton, M. and Hannan, M. (1996) "The Road Taken: Origins and Early Evolution of Employment Systems in Emerging Companies," Industrial and Corporate Change 5: 239-75.

Baron, J., Hannan, M. and Burton, M. (1999) "Building the Iron Cage: Determinants of Managerial Intensity in the Early Years of Organizations," American Sociological Review 64: 527-47.

Baum, J., Li, S. and Usher, J. (2000) "Making the Next Move: How Experiential and Vicarious Learning Shape the Locations of Chains' Acquisitions," Administrative Science Quarterly 45: 766-801.

Baum, J., McEvily, B. and Rowley, T. (2012) "Better with Age? Tie Longevity and the Performance Implications of Bridging and Closure.” Organization Science, 23: 529-546. 
Baum, J., Rowley, T. and Shipilov, A. (2004) "The Small World of Canadian Capital Markets: Statistical Mechanics of Investment Bank Syndicate Networks, 1952-1989," Canadian Journal of Administrative Sciences [Revue Canadienne Des Sciences De L Administration] 21(4): 307-25.

Baum, J., Shipilov, A. and Rowley, T. (2003) "Where Do Small-Worlds Come From?" Industrial and Corporate Change 12: 697-725.

Beckman, C. and Haunschild, P. (2002) "Network Learning: The Effects of Partners' Heterogeneity of Experience on Corporate Acquisitions," Administrative Science Quarterly 47: 92-124.

Boeker, W. (1988) "Organizational Origins: Entrepreneurial and Environmental Imprinting at the Time of Founding," in G. Carroll (ed.) Ecological Models of Organizations, pp. 33-51. Cambridge, MA: Ballinger Publishing.

Boeker, W. (1989) "Strategic Change: The Effects of Founding and History," Academy of Management Journal 32: 489-515.

Borgatti, S. P., Everett, M. G. and Freeman, L. C. (2002) UCINET for Windows: Software for Social Network Analysis. Harvard, MA: Analytic Technologies.

Brass, D. J., Galaskiewicz, J., Greve, H. and Tsai, W. (2004) "Taking Stock of Networks and Organizations: A Multilevel Perspective," Academy of Management Journal 47: 795-817.

Burt, R. S. (1980) “Autonomy in a Social Topology,” American Journal of Sociology 85: 892-925.

Burt, R. S. (1992) Structural Holes. Cambridge, MA: Harvard University Press.

Burt, R. S. (2000) "The Network Structure of Social Capital," Research in Organizational Behavior 22: 345-423.

Burt, R. S. (2002) "Bridge Decay," Social Networks 24: 333-63.

Burt, R. S. (2004) "Structural Holes and Good Ideas," American Journal of Sociology 110: 349-99.

Bygrave, W. and Timmons, J. (1992) Venture Capital at the Crossroads. Cambridge, MA: Harvard Business School Press.

Carroll, G. and Hannan, M. (1989) "Density Delay in the Evolution of Organizational Populations: A Model and Five Empirical Tests," Administrative Science Quarterly 34: 411-30.

Cochrane, J. H. (2005) "The Risk and Return of Venture Capital," Journal of Financial Economics 75: 3-52.

Coleman, J. S. (1988) "Social Capital in the Creation of Human Capital," American Journal of Sociology 94: S95-S120.

Davis, G., Yoo, M. and Baker, W. (2003) "The Small-World of the American Corporate Elite, 1982-2001," Strategic Organization 3: 301-26.

De Clercq, D., Fried, V. H., Lehtonen, O. and Sapienza, H. J. (2006) “An Entrepreneur's Guide to the Venture Capital Galaxy," Academy of Management Perspectives 20: 90-112.

DiMaggio, P. and Powell, W. (1983) "The Iron Cage Revisited: Institutional Isomorphism and Collective Rationality in Organizational Fields," American Sociological Review 48(2): 147-60.

Dimov, D. and Martin de Holan, P. (2010) "Firm Experience and Market Entry by Venture Capital Firms (1962-2004)," Journal of Management Studies 47(1): 130-61.

Eisenhardt, K. M. and Schoonhoven, C. B. (1990) "Organizational Growth: Linking Founding Team, Strategy, Environment, and Growth among U.S. Semiconductor Ventures," Administrative Science Quarterly 35: $504-29$.

Etzkowitz, H., Kemelgor, C. and Uzzi, B. (2000) Athena Unbound: The Advancement of Women in Science and Technology. Cambridge: Cambridge University Press.

Fleming, L., King, C. and Juda, A. (2007) "Small-Worlds and Regional Innovation," Organization Science 18: $938-54$.

Freeman, L. (1979) “Centrality in Social Networks: Conceptual Clarification,” Social Networks 1: 215-39.

Fried, V. and Hisrich, R. (1994) "Toward a Model of Venture Capital Investment Decision Making," Financial Management 23: 28-37.

Friedman, T. (2005) The World Is Flat: A Brief History of the Twenty-first Century. New York: Farrar, Straus and Giroux.

Galaskiewicz, J. (1979) "An Urban Grants Economy Revisited: Corporate Charitable Contributions in the Twin Cities, 1979-81, 1987-89,” Administrative Science Quarterly 42: 445-71. 
George, G., Kotha, R. and Zheng, Y. (2008) "Entry into Insular Domains: A Longitudinal Study of Knowledge Structuration and Innovation in Biotechnology Firms," Journal of Management Studies 45: 1448-74.

Gompers, P. and Lerner, J. (2001) “The Venture Capital Revolution,” The Journal of Economic Perspectives 15: 145-68.

Gould, R. V. and Fernandez, R. (1989) "Structures of Mediation: A Formal Approach to Brokerage in Transaction Networks," Sociological Methodology 19: 89-126.

Gupta, A. and Sapienza, H. (1992) "Determinants of Venture Capital Firms: Preferences Regarding the Industry Diversity and Geographic Scope of Their Investments," Journal of Business Venturing 7: 347-362.

Hannan, M. and Freeman, J. (1987) "The Ecology of Organizational Founding: American Labor Unions, 1836-1985," American Journal of Sociology 92: 910-43.

Hannan, M., Burton, D. and Baron, J. (1996) "Inertia and Change in the Early Years: Employment Relationships in Your High Technology Firms," Industrial and Corporate Change 5: 503-36.

Hansen, M. T. (1999) "The Search-Transfer Problem: The Role of Weak Ties in Sharing Knowledge Across Organization Subunits," Administrative Science Quarterly 44: 82-111.

Haunschild, P. and Miner, A. (1997) "Modes of Interorganizational Imitation: The Effects of Outcome Salience and Uncertainty," Administrative Science Quarterly 42: 475-500.

Haunschild, P. and Sullivan, B. N. (2002) "Learning from Complexity: Effects of Prior Accidents and Incidents on Airlines' Learning," Administrative Science Quarterly 47: 609-43.

Heckman, J. (1979) “Sample Selection Bias as a Specification error,” Econometrica 47: 153-61.

Hsu, D. (2006) "Venture Capitalists and Cooperative Start-up Commercialization Strategy," Management Science 52: 204-19.

Johnson, V. (2007) "What is Organizational Imprinting? Cultural Entrepreneurship in the Founding of the Paris Opera," American Journal of Sociology 113: 97-127.

Kim, T., Oh, H. and Swaminathan, A. (2006) "Framing Interorganizational Network Change: A Network Inertia Perspective," Academy of Management Review 31: 704-20.

Kogut, B. and Walker, G. (2001) "The Small-World of German Corporate Networks in the Global Economy," American Sociological Review 66: 317-35.

Kogut, B. and Zander, U. (1992) "Knowledge of the Firm, Combinative Capabilities, and the Replication of Technology," Organization Science 3: 383-97.

Kogut, B. and Zander, U. (2000) "Did Socialism Fail to Innovate? A Natural Experiment of the Two Zeiss Companies," American Sociological Review 65(2): 169-90.

Kyriazidou, E. (1997) “Estimation of a Panel Data Sample Selection Model,” Econometrica 65(6): $1335-1364$.

Larcker, D. F., So, E. C. and Wang, C.Y. (2012) Boardroom Centrality and Firm Performance. Harvard Business School Working Paper.

Lee, J-H., Choi, C. and Kim, J. M. (2012) “Outside Directors' Social Capital and Firm Performance: A Complex Network Approach,” Social Behavior and Personality: An International Journal 40: 1319-31.

Lerner, J. (1994) “The Syndication of Venture Capital Investments," Financial Management 23: 16-27.

McEvily, B. and Zaheer, A. (1999) "Bridging Ties: A Source of Firm Heterogeneity in Competitive Capabilities," Strategic Management Journal 20: 1133-56.

McEvily, B., Jaffee, J. and Tortoriello, M. (2012) "Not all Bridging Ties are Equal: Network Imprinting and Firm Growth in the Nashville Legal Industry, 1933-1978," Organization Science 23(2): 547-63.

March, J. (1991) "Exploration and Exploitation in Organizational Learning," Organization Science 2: 71-87.

Marquis, C. (2003) "The Pressure of the Past: Network Imprinting in Inter-Corporate Communities," Administrative Science Quarterly 48: 655-89.

Marquis, C. and Huang, Z. (2010) “Acquisitions as Exaptation: The Legacy of Founding Institutions in the U.S. Commercial Banking Industry,” Academy of Management Journal 53: 1441-73.

Marquis, C. and Tilcsik, A. (2013) "Imprinting: Toward a Multi-Level Theory," The Academy of Management Annals 7: 197-243.

Marsden, P. V. (1982) "Brokerage Behavior in Restricted Exchange Networks," in P. V. Marsden and N. Lin (eds) Social Structure and Network Analysis, pp. 201-18. Beverly Hills, CA: Sage. 
Meyer, J. W. and Rowan, B. (1977) "Institutionalized Organizations: Formal Structure as Myth and Ceremony," American Journal of Sociology 83: 41-62.

Mizruchi, M. and Stearns, L. (2000) Getting deals done: The use of social networks in bank decision making. Working Paper, University of Michigan, Ann Arbor, MI, June.

MoneyTree Survey (2004) PricewaterhouseCoopers. Arlington, VA: Thomson Venture Economics and the National Venture Capital Association.

Newman, M. (2000) “Models of the Small-World,” Journal of Statistical Physiology 101: 819-41.

Newman, M., Strogatz, S. and Watts, D. (2002) "Random Graph Models of Social Networks," Proceedings of the National Academy of Sciences of the United States of America 99: 2566-72.

Nijman, Th. E. and Verbeek, M. (1992) “Testing for Selectivity Bias in Panel Data Models," International Economic Review 33: 681-703.

Peng, M. and Luo, Y. (2000) "Managerial Ties and Firm Performance in a Transition Economy: The Nature of a Micro-Macro Link," Academy of Management Journal 43: 486-501.

Podolny, J. (2001) "Networks as the Pipes and Prisms of the Market," American Journal of Sociology 107: 33-60.

Podolny, J. and Feldman, A. (1997) Choosing ties from the inside of a prism: Egocentric uncertainty and status in the venture capital markets. Working Paper, Stanford University, Palo Alto, CA.

Reagans, R. E. and McEvily, B. (2003) "Network Structure and Knowledge Transfer: The Effects of Cohesion and Range," Administrative Science Quarterly 48: 240-67.

Romanelli, E. (1989) "Environments and Strategies of Organizational Start-Ups: Effects on Early Survival," Administrative Science Quarterly 34: 369-87.

Schilling, M. and Phelps, C. (2007) "Interfirm Collaboration Networks: The Impact of Large-Scale Network Structure on Firm Innovation,” Management Science 53: 1113-26.

Siggelkow, N. and Levinthal, D. A. (2003) "Temporarily Divide to Conquer: Centralized, Decentralized, and Reintegrated Organizational Approaches to Exploration and Adaptation," Organization Science 14: 650669.

Soda, G., Usai, A. and Zaheer, A. (2004) "Network Memory: The Influence of Past and Current Networks on Performance," Academy of Management Journal 47: 893-906.

Sorenson, O. and Stuart, T. (2001) "Syndication Networks and the Spatial Distribution of Venture Capital Investments," American Journal of Sociology 106: 1546-88.

Stinchcombe, A. L. (1965) "Social Structures and Organizations," in J. G. March (ed.) Handbook of Organizations, pp. 142-93. Chicago, IL: Rand McNally.

Sullivan, B. N. and Tang, Y. (2012) "Small-World Networks, Absorptive Capacity, and Firm Performance: Evidence from the U.S. Venture Capital Industry," International Journal of Strategic Change Management 4(2): 149-75.

Sullivan, B. N. and Tang, Y. (2013) "Which Signal to Rely On? The Impact of the Quality of Board Interlocks and Inventive Capabilities on R\&D Alliance Formation under Uncertainty," Strategic Organization 11: 364-88.

Sullivan, B. N., Haunschild, P. and Page, K. (2007) “Organizations Non Gratae? The Impact of Unethical Corporate Behavior on Interorganizational Networks,” Organization Science 18: 55-70.

Swaminathan, A. (1996) "Environmental Conditions at Founding and Organizational Mortality: A Trial-byFire Model," Academy of Management Journal 39: 1350-77.

Tucker, D. J., Singh, J. V. and Meinhard, A. G. (1990) "Founding Characteristics, Imprinting and Organizational Change," in J. V. Singh (ed.) Organizational Evolution: New Directions, pp. 182-200. Newbury Park, CA: Sage.

Uzzi, B., Amaral, L. and Reed-Tsochas, F. (2007) "Small-World Networks and Management Science Research: A Review," European Management Review 4: 77-91.

Uzzi, B. and Spiro, J. (2005) "Collaboration and Creativity: The Small-World Problem,” American Journal of Sociology 111: 447-504.

Verspagen, B. and Duysters, G. (2004) “The Small-Worlds of Strategic Technology Alliances," Technovation 24: $563-71$. 
Walker, G., Kogut, B. and Shan, W. (1997) "Social Capital, Structural Holes and the Formation of an Industry Network," Organization Science 8: 109-25.

Wasserman, S. and Faust, K. (1998) Social Network Analysis: Methods and Application. Cambridge: Cambridge University Press.

Watts, D. (1999) Small-Worlds: The Dynamics of Networks between Order and Randomness. Princeton, NJ: Princeton University Press.

Yamaguchi, K. (1994) "The Flow of Information through Social Networks: Diagonal-Free Measures of Inefficiency and the Structural Determinants of Inefficiency," Social Networks 16: 57-86.

\section{Author biographies}

Bilian Ni Sullivan is an associate professor in the Department of Management, Hong Kong University of Science and Technology. She received her PhD from the Graduate School of Business, Stanford University. Bilian's current research focuses on extending the behavioral theories of the firm in the context of firm innovation, especially for Chinese firms. Her work has been published in Administrative Science Quarterly, Organization Science, and other journals. Bilian is currently a Senior Editor of Management and Organization Review. She also serves on the Editorial Board of Organization Science.

Yi Tang is an assistant professor in the Department of Management and Marketing, Hong Kong Polytechnic University. He received his PhD from the Department of Management, Hong Kong University of Science and Technology. His recent research examines how corporate executives' psychological biases affect firm decision and performance. Yi's research has been published in leading management journals such as Academy of Management Journal, Strategic Management Journal, and Journal of Management. Yi currently serves on the editorial board of Strategic Management Journal.

Christopher Marquis is Visiting Professor of Management at the Johnson Graduate School of Management at Cornell University. He received his PhD in Sociology and Organizational Behavior from the University of Michigan. His current research focus is the sustainability and corporate social responsibility strategies of global corporations, with a particular emphasis on firms in China. Theoretically, this research builds on his prior work on unpacking the mechanisms of how and why firm behavior varies over time and across geographic contexts. Marquis is an Associate Editor at Administrative Science Quarterly and an elected member of the executive committee of the Organization and Management Theory Division of the Academy of Management. 